\title{
The Additional Effect of Hyaluronidase in Lumbar Interlaminar Epidural Injection
}

Sang Beom Kim, M.D., Kyeong Woo Lee, M.D., Jong Hwa Lee, M.D., Min Ah Kim, M.D., Byung Hee Kim, M.D.

Department of Physical Medicine and Rehabilitation, Dong-A University College of Medicine, Busan 602-715, Korea

Objective To evaluate the effect of hyaluronidase in lumbar interlaminar epidural injection (LIEI) for low back pain and sciatica.

Method Sixty-one patients suffering from severe low back pain and sciatica were randomly allocated into three groups. Group $\mathrm{T}$ ( $\mathrm{n}=18$, mean duration of illness: $2.12 \pm 1.16$ months) received lumbar interlaminar epidural injection (LIEI) with $2 \mathrm{ml}$ triamcinolone $(40 \mathrm{mg} / \mathrm{ml})$ and $5 \mathrm{ml}$ bupivacaine $(0.25 \%)$. Group $\mathrm{H}$ ( $\mathrm{n}=16$, mean duration of illness: $2.05 \pm 1.12$ months) received LIEI with 1,500 IU hyaluronidase and $5 \mathrm{ml}$ bupivacaine (0.25\%). Group TH ( $\mathrm{n}=27$, mean duration of illness: $2.16 \pm 1.65$ months) received LIEI with 1,500 IU hyaluronidase, $2 \mathrm{ml}$ triamcinolone $(40 \mathrm{mg} / \mathrm{ml})$, and $5 \mathrm{ml}$ bupivacaine $(0.25 \%)$. The effects were evaluated using the Visual Analogue Scale (VAS) and Oswestry Disability Index (ODI) at preinjection and 2 weeks, 4 weeks, and 8 weeks after LIEI.

Results Pain improved in all groups after 2 weeks $(\mathrm{p}<0.05)$. After 8 weeks, there was no significant difference in VAS improvement among the 3 groups. However, pain improved in $70.4 \%$ of Group TH compared with preinjection, in contrast to $44.4 \%$ of Group T and $31.3 \%$ of Group H. The ODI improved significantly only in Group TH after 8 weeks $(\mathrm{p}<0.05)$.

Conclusion LIEI with triamcinolone and hyaluronidase is more effective for reducing pain after 8 weeks than injection with triamcinolone or hyaluronidase alone.

Key Words Hyaluronidase, Low back pain, Sciatica, Epidural injection

\section{INTRODUCTION}

Low back pain and lower extremity radiating pain are conditions suffered by $80 \%$ of the entire population at least once in their lifetime, ${ }^{1}$ and treatments for these conditions include conservative treatments such as bed rest, drug treatment, and physical therapy, and

Received June 11, 2010; Accepted November 10, 2010

Corresponding author: Kyeong Woo Lee

Department of Physical Medicine and Rehabilitation, Dong-A University College of Medicine, 3-ga, Dongdaeshin-dong, Seo-gu, Busan 602-715, Korea

Tel: +82-51-240-5690, Fax: +82-51-254-8511, E-mail: kwlee65@dau.ac.kr Copyright $\odot 2011$ by Korean Academy of Rehabilitation Medicine surgical therapy (such as discectomy), as well as epidural injections that can be implemented between conservative treatment and surgical therapy. Epidural injections are an important treatment method that can relieve initial symptoms and reduce the need for surgery. ${ }^{2}$

It has been revealed that local injections of steroids and local anesthetics can relieve both the pain caused by mechanical pressure ${ }^{3}$ and the pain caused by inflammatory responses resulting from TNF- $\alpha^{4}$ and $\mathrm{NO}_{2}{ }^{5}$ existing in nucleus pulposus cells; as such, steroids and local anesthetics are used as major drugs for epidural injections.

However, McLain et al. ${ }^{6}$ reported that when epidural steroid injections had been implemented with a 
transforaminal approach, among the $50-75 \%$ of subjects who showed temporary relief of symptoms, only $25-57 \%$ showed long-term pain relief and thus, while steroid administration was effective in some patients with neuropathy, the duration of the effects was quite limited.

Hyaluronidase is a drug that was tested to improve the effect of epidural injections using steroids and to extend the duration of the effect. Hyaluronidase is characterized by its actions to remove barriers between tissues by hydrolyzing glucosaminic bonds between hyaluronic acid, a major intercellular material, and connective tissues to dissolve the bonds and relieve fibroplasia in tissues. It is also known that hyaluronidase acts to relieve swelling and edema in tissues. ${ }^{7}$ Hyaluronidase is being used in the areas of ophthalmology and anesthesiology to remove scar tissue and to increase the tissue permeability of injections.

The use of hyaluronidase should be avoided in patients who show hypersensitivity reactions to bovine proteins, in areas of infection or swelling, in patients with congenital heart defects, in venous congestion patients, and in patients with genetic problems such as galactose intolerance or lactase deficiency. It has been reported that if hyaluronidase is used in accordance with recommended methods of use, there are no serious adverse effects.

In Korea, results have been published regarding studies that verified the effects of hyaluronidase on failed back surgery syndrome patients and cervical or lumbar herniated intervertebral disc patients, but the studies had limitations, such as small numbers of patients in subject groups, lack of a control group, or failure to adjust factors that could affect patients' treatment effects, such as combination treatments after the intervention. ${ }^{7,8}$

In this respect, to determine whether there are additional effects of hyaluronidase in epidural injections administered to herniated intervertebral disc patients, we conducted a prospective randomized controlled study on a total of 101 patients.

\section{MATERIALS AND METHODS}

\section{Study subjects}

Among patients who visited the hospital between January 2010 and April 2010 with low back pain and lower extremity radiating pain as chief complaints, 101 patients were randomly divided into 3 groups who apparently had low back pain or lower extremity radiating pain resulting from lumbar herniated intervertebral discs based on clinical findings, the results of physical examinations, and the results of magnetic resonance imaging. Patients who had undergone surgery in the past and those with spinal stenosis or a facet joint syndrome were excluded from the study.

\section{Study method}

The 101 patients were randomly divided into 3 groups named $\mathrm{T}, \mathrm{H}$, and $\mathrm{TH}$, based on the types of drugs to be injected. The epidural injections, which were implemented using the interlaminar approach, were administered after having the patients take a lateral decubitus position with a posture of flexed neck, pelvis, and knees. The skin and subcutaneous tissues were anesthetized by injecting 1-2 $\mathrm{ml}$ of $1 \%$ lidocaine between the \#4 and \#5 spinous processes of the lumbar vertebrae, and a 20-gauge Tuohy needle was inserted $2-3 \mathrm{~cm}$ so as to enter the interspinal ligament. Then, a syringe containing air was attached to the needle, and the needle was slowly pushed forward, 1-2 $\mathrm{mm}$ at a time, until the absence of resistance was felt. The location of the needle was identified by injecting $2 \mathrm{ml}$ of a non-ionic contrast medium and seeing the upward diffusion of the contrast medium in the form of a thin line.

When the needle was identified at an epidural location, injections were administered as follows: group $\mathrm{T}$ $(\mathrm{n}=30)$, received a local anesthetic and a steroid $(2 \mathrm{ml}$ of triamcinolone, $40 \mathrm{mg} / \mathrm{ml}$ and $5 \mathrm{ml}$ of bupivacaine, $0.25 \%)$; group $\mathrm{H}(\mathrm{n}=32)$, received a local anesthetic and hyaluronidase (1,500 IU of hyaluronidase and $5 \mathrm{ml}$ of bupivacaine, $0.25 \%)$; and group $\mathrm{TH}(\mathrm{n}=39)$, received a local anesthetic, a steroid, and hyaluronidase (1,500 IU of hyaluronidase, $2 \mathrm{ml}$ of triamcinolone, $40 \mathrm{mg} / \mathrm{ml}$, and 5 $\mathrm{ml}$ of bupivacaine, $0.25 \%$ ).

The effects of the intervention were evaluated by measuring Visual Analogue Scales (VAS) and Oswestry Disability Indexes (ODI) before the intervention and at 2 weeks, 4 weeks, and 8 weeks after the intervention to determine whether hyaluronidase was effective for long-term reductions of pain. The ratios of patients who showed $50 \%$ or larger reductions in pain based on VAS values at 2 weeks and 4 weeks after the intervention were calculated by group. 
To control factors that could affect the patients' treatment effects, the same series of oral drugs was prescribed to the patients who participated in the study for 2 weeks after their first visit to the hospital. No physical treatment was implemented after the injection treatment. Fifteen patients who received combination treatments such as physical therapy and Chinese medicine treatments at other medical institutions, 6 patients who could not take drugs due to gastrointestinal disorders or hypersensitivity reactions to drugs, and 19 patients who had not followed up were excluded from the study.

\section{Statistics}

Statistical analysis was conducted using the SPSS 14.0 statistical program for Windows. Analysis of variance

Table 1. Demographic Data

\begin{tabular}{lccc}
\hline & T (n=18) & H (n=16) & TH $(\mathbf{n}=\mathbf{2 7})$ \\
\hline Age (years) & 61.07 & 61.25 & 60.47 \\
Sex (male/female) & $8 / 10$ & $7 / 9$ & $11 / 16$ \\
Weight $(\mathrm{kg})$ & 63.27 & 64.48 & 61.56 \\
Height $(\mathrm{cm})$ & 164.14 & 164.20 & 164.56 \\
Diagnosis & & & \\
$\quad$ Lumbar HIVD & 16 & 15 & 25 \\
$\quad \begin{array}{l}\text { Lumbar HIVD with } \\
\quad \text { spondylolisthesis }\end{array}$ & 2 & 1 & 2 \\
\hline
\end{tabular}

HIVD: Herniated intervertebral disc, T: Triamcinolone and bupivacaine, $\mathrm{H}$ : Hyaluronidase and bupivacaine, TH: Triamcinolone, hyaluronidase, and bupivacaine
(ANOVA) was used to compare degrees of change in VAS and ODI among the three groups before the intervention, and at 2, 4, and 8 weeks after the intervention. Cases which $p$-values were $\leq 0.05$ were judged to be statistically significant.

\section{RESULTS}

Of the 101 patients, 16 patients were excluded from the study 2 weeks after the intervention and, of the remaining 85 patients, 24 were excluded from the study 8 weeks after the intervention; thus, a total of 61 patients participated in the study until 8 weeks after the intervention. Except for male/female sex ratios, there were no significant differences in age, height, and causal diseases among the three groups (Table 1). No significant difference was observed among the 3 groups in either VAS or ODI before the intervention ( $p>0.05)$ (Table 2). At 2 weeks after the intervention, $78.3 \%$ of group $\mathrm{T}, 73.1 \%$ of group $\mathrm{H}$, and $88.9 \%$ of group TH answered that their pain was relieved. The degree of favorable change in VAS at 2, 4, and 8 weeks after the intervention compared to the values before the intervention was shown to be highest in group $\mathrm{TH}$, followed by group $\mathrm{T}$, and group $\mathrm{H}$ in order of precedence (Fig. 1), but the differences among the 3 groups were not statistically significant (Table 3 ). Regarding ODI, improvements were observed in all 3 groups and, whereas there was no significant difference in degree of change among the 3 groups at 2 and 4 weeks after the intervention, significantly larger improvements were observed in group TH compared to groups $\mathrm{T}$ and

Table 2. Comparison of Mean Visual Analog Scale and Oswestry Disability Index in Each Group

\begin{tabular}{|c|c|c|c|}
\hline & $\mathbf{T}$ & $\mathbf{H}$ & TH \\
\hline \multicolumn{4}{|c|}{ Visual analog scale } \\
\hline Pre-injection & $6.77 \pm 2.47$ & $6.53 \pm 1.74$ & $6.90 \pm 2.06$ \\
\hline After 2 weeks & $4.40 \pm 2.32$ & $5.42 \pm 2.12$ & $4.61 \pm 2.13$ \\
\hline After 4 weeks & $3.95 \pm 2.12$ & $4.68 \pm 2.24$ & $4.18 \pm 2.30$ \\
\hline After 8 weeks & $3.95 \pm 2.44$ & $5.00 \pm 2.83$ & $3.40 \pm 2.09$ \\
\hline \multicolumn{4}{|c|}{ Oswestry disability index } \\
\hline Pre-injection & $23.79 \pm 10.81$ & $18.00 \pm 7.89$ & $21.56 \pm 9.04$ \\
\hline After 2 weeks & $17.88 \pm 10.29$ & $15.08 \pm 6.82$ & $16.88 \pm 7.94$ \\
\hline After 4 weeks & $16.61 \pm 9.29$ & $15.47 \pm 8.57$ & $15.28 \pm 8.33$ \\
\hline After 8 weeks & $16.05 \pm 10.86$ & $16.88 \pm 11.84$ & $12.77 \pm 7.18$ \\
\hline
\end{tabular}

T: Triamcinolone and bupivacaine, H: Hyaluronidase and bupivacaine, TH: Triamcinolone, hyaluronidase, and bupivacaine. 


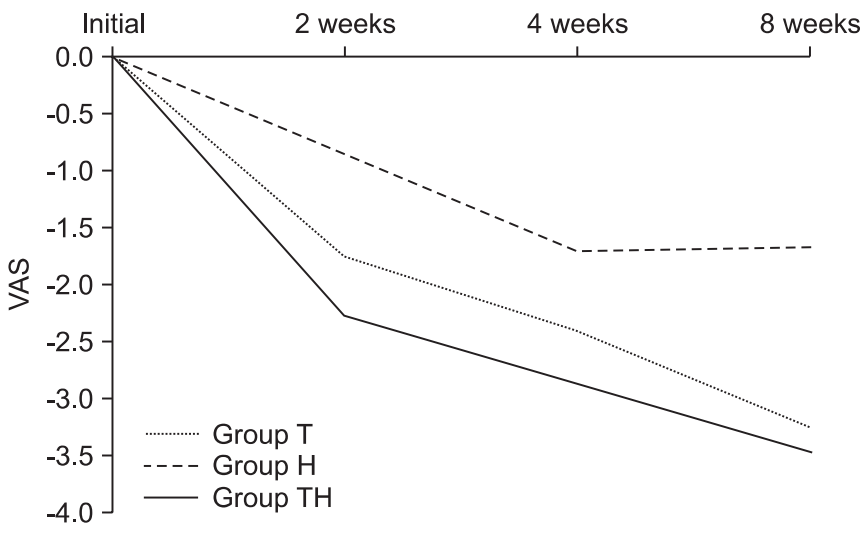

Fig. 1. Comparison of mean change of Visual Analogue Scale. T: Triamcinolone and Bupivacaine, $\mathrm{H}$ : Hyaluronidase and Bupivacaine, TH: Triamcinolone, Hyaluronidase, and Bupivacaine

Table 3. Comparison of the Mean Decrease of VAS and ODI among $\mathrm{T}$ group, $\mathrm{H}$ group, and $\mathrm{TH}$ group

\begin{tabular}{|ccccc|}
\hline & T & H & TH & p-value \\
\hline Mean decrease of VAS & & & & \\
\hline After 2 weeks & -1.76 & -0.85 & -2.28 & 0.065 \\
\hline After 4 weeks & -2.41 & -1.71 & -2.89 & 2.298 \\
\hline After 8 weeks & -3.26 & -1.68 & -3.48 & 0.070 \\
\hline Mean decrease of ODI & & & & \\
\hline After 2 weeks & -6.16 & -4.62 & -3.64 & 0.067 \\
\hline After 4 weeks & -7.73 & -4.88 & -6.80 & 0.30 \\
\hline After 8 weeks & -6.68 & -1.75 & $-8.26^{*}$ & 0.005 \\
\hline
\end{tabular}

VAS: Visual Analog Scale, ODI: Oswestry Disability Index, $\mathrm{T}$ : Triamcinolone and bupivacaine, H: Hyaluronidase and bupivacaine, TH: Triamcinolone, hyaluronidase, and bupivacaine

${ }^{*} \mathrm{p}<0.05$

$\mathrm{H}$ at 8 weeks after the intervention $(\mathrm{p}<0.05)($ Fig. 2). The ratios of patients who showed at least $50 \%$ reduction in pain based on VAS values at 2 and 8 weeks after the intervention were calculated by group and, based on the results (Table 4), it was found that pain was reduced in $33.3 \%$ of group T, $12.4 \%$ of group $\mathrm{H}$, and at least $50 \%$ of group TH at 2 weeks after the intervention. However, at 8 weeks after the intervention, pain was reduced by at least $50 \%$ compared to before the intervention in $44.4 \%$ of group T, $31.3 \%$ of group H, and $70.4 \%$ of group TH (Fig. 3 ).

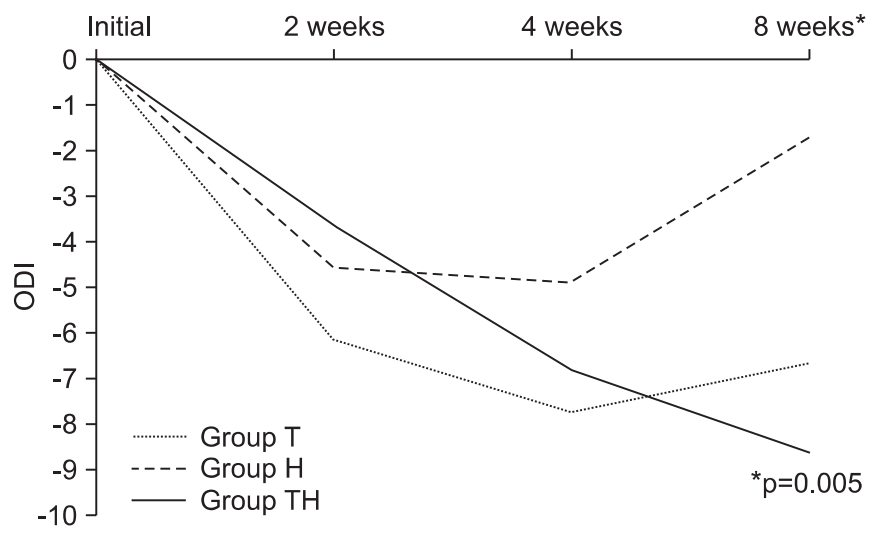

Fig. 2. Comparison of mean change of Oswestry Disability Index. T: Triamcinolone and Bupivacaine, $\mathrm{H}$ : Hyaluronidase and Bupivacaine, TH: Triamcinolone, Hyaluronidase, and Bupivacaine.

${ }^{*} \mathrm{p}<0.05$

Table 4. Patients with > 50\% Pain Relief as Measured by VAS

\begin{tabular}{lccc}
\hline & T & H & TH \\
\hline After 2 weeks & $6 / 18(33.3 \%)$ & $2 / 16(12.4 \%)$ & $7 / 27(25.9 \%)$ \\
After 4 weeks & $8 / 18(44.4 \%)$ & $5 / 16(31.3 \%)$ & $19 / 27(70.4 \%)$ \\
\hline $\begin{array}{l}\text { VAS: Visual Analog Scale, T: Triamcinolone and Bupiva- } \\
\text { caine, H: Hyaluronidase and Bupivacaine, TH: Triam- } \\
\text { cinolone, Hyaluronidase, and Bupivacaine }\end{array}$ \\
DISCUSSION
\end{tabular}

The intent of this study was to determine if epidural injections supplemented with hyaluronidase were beneficial for improving pain relief effects and for extending the duration of pain relief. Based on the results of this study, it can be seen that epidural injections of steroids and local anesthetics supplemented with hyaluronidase could maintain pain relief and reduce inconveniences in daily life for relatively long periods of time, thereby increasing the effects of epidural injections. For low back pain and lower extremity radiating pain resulting from herniated intervertebral discs, epidural injections using steroid and local anesthetic mixed solutions are a treatment recommended as a stage prior to surgery, because its effects were proved in cases where symptoms were not relieved, even after a long period of conservative treatment. However, to examine the durability of treatment effects, Carette et al. ${ }^{9}$ and WilsonWilson-MacDonald et al. ${ }^{10}$ conducted a randomized 

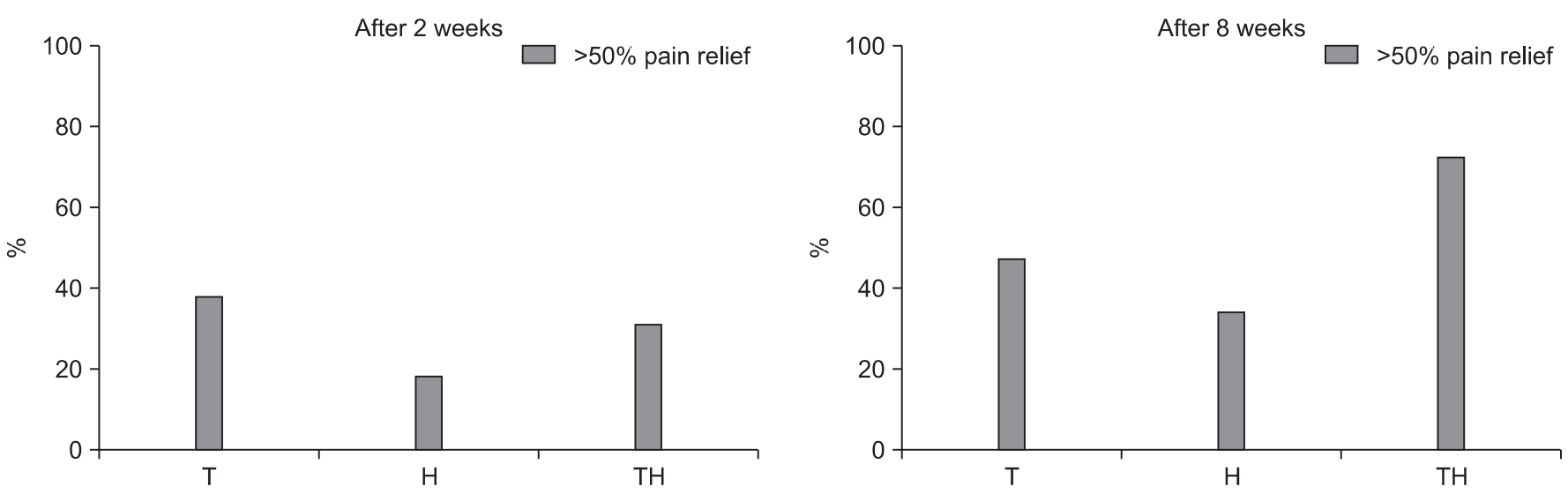

Fig. 3. Pain relief $>50 \%$ as measured by Visual Analogue Scale. T: Triamcinolone and Bupivacaine, H: Hyaluronidase and Bupivacaine, TH: Triamcinolone, Hyaluronidase, and Bupivacaine

controlled study on patients with radiculopathy and reported that although steroids were effective in relieving early stage pain, they did not have long-term benefits.

Carette et al. ${ }^{9}$ published a report indicating that significant pain relief and improved functions were observed in an experimental group injected with $8 \mathrm{ml}$ of a steroid and normal salinemixed solution, compared to a control group that received epidural injections of $1 \mathrm{ml}$ of normal saline; but based on the results of calculations of accumulated probabilities of undergoing back surgery by 12 months later, there was no significant difference between the two groups. In addition, Buchner et al., ${ }^{11}$ who compared the effects of epidural injections with the effects of physical therapy, reported that although significant pain relief was observed in a group that received epidural injections compared to a control group that received physical therapy during the initial 2 weeks, there was no substantial improvement in mid-long-term followup observations thereafter. As such, regarding the effects of epidural injections, it is suggested that the reason steroids show effects during initial short periods, but the duration of the effects is limited, is because steroids cannot greatly affect the processes of fibrocyte proliferation, collagen deposition, and cicatrization around nerve roots occurring in the latter stages of inflammatory processes. ${ }^{8}$

Hyaluronidase is a drug that has been tested to overcome the limited duration and effects of existing epidural injections. In Korea, Lee et al. ${ }^{7}$ reported good results when they injected hyaluronidase along with steroids in 10 patients who were suffering from pain due to tissue synechia around nerve roots as part of failed back surgery syndromes, ${ }^{12}$ because hyaluronidase was known to remove barriers between tissues and reduce fibroplasia in tissues, as well as reduce swelling and edema. Jo et al. ${ }^{8}$ reported that during transforaminal epidural injections, they evaluated pain relief for 6 months in a group injected with steroids and local anesthetics only, and in another group injected with a mixed solution containing steroid, local anesthetic, and hyaluronidase. Results showed that pain relief continued in a few more patients in the latter group, although the differences were not statistically significant.

Previous studies had limitations for evaluating the additional effects of hyaluronidase in epidural injections due to the absence of a control group; failure to adjust factors that could affect patients' treatment effects such as combination treatments after the intervention or differences in oral drugs; and small numbers of patients in subject groups. In this study, a total of 61 patients with low back pain or lower extremity radiating pain resulting from herniated intervertebral discs were divided into 3 groups: a group injected with steroids and local anesthetics (group T); a group injected with hyaluronidase and local anesthetics (group $\mathrm{H}$ ); and a group injected with steroid, local anesthetic, and hyaluronidase (group TH) to evaluate not only the additional effects of hyaluronidase but also its singular effects in epidural injections.

In this study, the ratios of patients who showed at least $50 \%$ VAS reduction after the intervention were determined and, based on the results, clear differences were observed at 8 weeks after the intervention. The ratios of groups $\mathrm{T}$ and $\mathrm{H}$ were $44.4 \%$ and $31.3 \%$ 
respectively, while the ratio of group TH was $70.4 \%$. Significant improvements in ODI were also observed in group $\mathrm{TH}$ as compared to groups $\mathrm{T}$ and $\mathrm{H} 8$ weeks after intervention. That is to say, in the early stage after the intervention, similar degrees of pain relief were observed in groups $\mathrm{T}$ and $\mathrm{TH}$ due to the inflammation suppressing effects of steroids but, as time went on, group TH showed superior effects compared to group $\mathrm{T}$ in the extension of the duration of pain relief and the degree of subjective inconvenience. This is believed to be because hyaluronidase not only suppressed fibroplasia, collagen deposition, and cicatrization to contribute to pain relief, but also enhanced steroid permeation to bring added synergistic effects for pain relief. These results are different from the results of a study by Devulder et al., ${ }^{13}$ which indicated that in 1-, 3-, and 6-month followup observations after selective epidural nerve root sleeve injections in patients with failed back surgery syndromes, there was no significant difference among the 3 groups, and that the differences are attributable to differences in the composition of lumbar part diseases of experimental subject groups and the injection methods.

A comparison of group $\mathrm{T}$ and group $\mathrm{H}$ showed that not only the average values of VAS improved at 2, 4, and 8 weeks after the intervention, but also the ratios of patients with at least $50 \%$ pain relief at 2 and 8 weeks after the intervention were higher in group $\mathrm{T}$. This suggests that the degree of contribution to the effects of epidural injections for pain relief resulting from steroids' suppression of inflammation was higher than that of hyaluronidase's suppression of inflammatory responses in the latter stage.

Limitations of this study include the fact that, although we attempted to determine the long-term effects of hyaluronidase when only drug treatments were implemented after injections, the patients' compliance declined over time, and thus the results were observed only up to 8 weeks. Also, local anesthetics were included in all 3 groups and thus there were difficulties in judging the singular effects of hyaluronidase. In addition, although it was determined that VAS and ODI were not statistically different among the three groups before the intervention, the patients were not classified by the degree of herniated intervertebral disc. We propose that the effects of hyaluronidase can be more accurately evaluated if future studies on patients with failed back surgery syndromes using diverse injection methods are conducted after classifying patients by the degree of herniated intervertebral disc, and by including local anesthetic and hyaluronidase single-administration groups.

\section{CONCLUSION}

We observed the additional effects of hyaluronidase in lumbar epidural injections on 61 patients with low back pain or lower extremity radiating pain resulting from herniated intervertebral disc. At the early stage (2 weeks after the intervention), similar degrees of pain relief were observed in group $\mathrm{T}$ and group $\mathrm{TH}$ due to the inflammation suppressing effects of steroids. However, as time progressed, group TH showed superior effects compared to group $\mathrm{T}$ for the extension of the duration of pain relief and the degree of subjective inconvenience. Therefore, it is suggested that epidural injections using hyaluronidase and steroid mixed solutions are more effective than single steroid therapy not only for extending the duration of pain relief, but also for reducing patients' sense of inconvenience.

\section{ACKNOWLEDGEMENTS}

This study was supported by research fund from Dong-A University Medical Center $<09-10-156>$ and a grant of the Korea Healthcare Technology R\&D Project, Ministry of Health \& Welfare, Republic of Korea (A070001).

\section{REFERENCES}

1. Andersson GB. Epidemiological features of chronic low-back pain. Lancet 1999; 354: 581-585

2. Jung SG. Epidural steroid injection in lumbosacral radiculopathy (due to herniated intervertebral disc) efficacy-randomized placebo controlled studies. Korean J Pain 2007; 6: 14-23

3. Hayashi N, Weinstein JN, Meller ST, Lee HM, Spratt KF, Gebhart GF. The effect of epidural injection of betamethasone or bupivacaine in a rat model of lumbar radiculopathy. Spine 1998; 23: 877-885

4. Murata Y, Onda A, Rydevik B, Takahashi K, Olmarker K. Distribution and appearance of tumor necrosis factor-alpha in the dorsal root ganglion exposed to 
experimental disc herniation in rats. Spine 2004; 29 : 2235-2241

5. Brisby H, Byröd G, Olmarker K, Miller VM, Aoki Y, Rydevik B. Nitric oxide as a mediator of nucleus pulposus-induced effects on spinal nerve roots. J Orthop Res 2000; 18: 815-820

6. McLain RF, Kapural L, Mekhail NA. Epidural steroid therapy for back and leg pain; mechanism of action and efficacy. Spine J 2005; 5: 191-201

7. Lee KJ, Han SG, Yoon SH, Kim JS, Lee YS. Nerve root block with corticosteroids, hyaluronidase, and local anesthetic in the failed back surgery syndrome. Korean J Pain 1999; 12: 191-194

8. Jo DH, Hong JH, Kim MH. The effect of transforaminal epidural block with hyaluronidase and triamcinolone. Korean J Pain 2005; 18: 176-180

9. Carette S, Leclaire R, Marcoux S, Morin F, Blaise GA, St-Pierre A, Truchon R, Parent F, Levesque J, Bergeron $\mathrm{V}$, et al. Epidural corticosteroid injections for sciatica due to herniated nucleus pulposus. N Engl J Med 1997; 336: 1634-1640

10. Wilson-MacDonald J, Burt G, Griffin D, Glynn C. Epidural steroid injection for nerve root compression. A randomised, controlled trial. J Bone Joint Surg $\mathrm{Br}$ 2005; 87: 352-355

11. Buchner M, Zeifang F, Brocai DR, Schiltenwolf M. Epidural corticosteroid injection in the conservative management of sciatica. Clin Orthop Relat Res 2000; 375: 149-156

12. Menzel EJ, Farr C. Hyaluronidase and its substrate hyaluronan: biochemistry, biological activities and therapeutic uses. Cancer Lett 1998; 131: 3-11

13. Devulder J, Deene P, De Laat M, Van Bastelaere M, Brusselmans G, Rolly G. Nerve root sleeve injections in patients with failed back surgery syndrome: a comparison of three solutions. Clin J Pain 1999; 15: $132-135$ 